\title{
SYNCHRONIZATION OF GEOMAGNETIC AND IONOSPHERIC DISTURBANCES OVER KAZAN STATION
}

\section{O.M. Barkhatova}

Nizhny Novgorod State University of Architecture and Civil Engineering,

Nizhny Novgorod, Russia, o.barkhatova@inbox.ru

Kozma Minin Nizhniy Novgorod State Pedagogical University, Nizhniy Novgorod, Russia, o.barkhatova@inbox.ru

\section{N.V. Kosolapova}

Kozma Minin Nizhniy Novgorod State Pedagogical University, Nizhniy Novgorod, Russia, natashakosolapova@mail.ru

\section{N.A. Barkhatov}

Kozma Minin Nizhniy Novgorod State Pedagogical University, Nizhniy Novgorod, Russia, nbarkhatov@inbox.ru

\section{S.E. Revunov}

Kozma Minin Nizhniy Novgorod State Pedagogical University, Nizhniy Novgorod, Russia,revunov@inbox.ru

\begin{abstract}
The phenomena which accompany synchronization of night-time ionospheric and geomagnetic disturbances in an ULF range with periods 35-50 min near the mid-latitude station Kazan during a global magnetically quiet period have been analyzed. The comparison between dynamic spectra and wavelet patterns of these disturbances has revealed that spectral features of simultaneous disturbances of the F2-layer critical frequency and $H, D, Z$ geomagnetic field components are similar. By studying spectral features of the F2-layer critical frequency over Kazan and disturbances of the $H$ and $D$ geomagnetic field components at magnetic stations which differ from Kazan station in longi-
\end{abstract}

tude and latitude, we have established that the disturbances considered belong to the class of fast magnetosonic waves. The analysis of solar wind parameters, interplanetary magnetic field (IMF), and values of the auroral index $A L$ in the period under study has shown that this event is associated with IMF $B_{z}$ component disturbances and occurs during substorm development.

Keywords: ionospheric disturbances, geomagnetic field disturbances, interplanetary magnetic field, substorm, magnetohydrodynamic disturbances

\section{INTRODUCTION}

One of the important aims of the study of ionospheric and geomagnetic disturbances is to find natural and artificial sources of magnetohydrodynamic (MHD) waves. It is well known that Earth's magnetosphere is a natural resonator for Alfvén, fast (FMS), and slow magnetosonic (SMS) waves [Guglielmi, Troitskaya, 1973]. Propagation of Alfvén and SMS waves is related to the geomagnetic field. When these waves are reflected from the conducting ionosphere, standing MHD waves emerge in the magnetosphere. A source of these waves in Earth's magnetosphere can be a fast magnetic sound. In turn, FMS waves can penetrate into the magnetosphere from the solar wind (SW) or be generated by the Kelvin-Helmholtz instability at the magnetopause when flowed around by SW [Mishin, Tomozov, 2014]. The propagation velocity of MHD disturbances in the magnetosphere can vary from hundreds to thousands of kilometers per second. Such fluctuations are currently associated with geomagnetic pulsations - ultralowfrequency (ULF) periodic magnetospheric disturbances whose frequency range is from $1 \mathrm{mHz}$ to $5 \mathrm{~Hz}$.

The appearance of MS waves in the magnetosphereionosphere system is often associated with the development of a geomagnetic storm. For example, Vorontsova et al. [2016] detected Pc5 geomagnetic pulsations in the recovery phase of a strong magnetic storm. During these pulsations, GPS data showed an increase in the total electron content (TEC) at the F2-layer height. The authors suggested that an MS wave can be responsible for the simultaneous plasma and geomagnetic disturbances. However, the excitation of MHD waves in the magnetosphere and conducting ionospheric layers may not necessarily be due to the development of global geomagnetic disturbances. For example, Barkhatova et al. [2009, 2015] have identified MS waves generated by the eastward electrojet and largemagnitude earthquakes. In addition, along with geomagnetic disturbances in the ULF range there were synchronous disturbances in the conducting F2 layer.

The main purpose of this study is to analyze the phenomena accompanying the synchronous night-time ionospheric and magnetic disturbances, which was observed under global magnetically quiet conditions from per minute data acquired at Kazan station. The phenomenon under study was short-lived and was observed for $50 \mathrm{~min}$ in the frequency range from 0.5 to $1 \mathrm{MHz}$ (periods 15-30 $\mathrm{min})$, i.e. in the region of ULF oscillations. The synchronization suggests that the discovered disturbances are magnetosonic. To identify characteristic parameters of these ionospheric and magnetic disturbances, we have adopted methods of dynamic and spectral wavelet analysis, sufficient to establish the frequency range and times of their synchronization. For the time of occurrence of the MS disturbances under study near Kazan station, we have examined geomagnetic variations at stations remote from Kazan station in longitude and latitude. To find causes of the disturbances, during their recording we analyzed extramagnetospheric processes involving changes in the dynamics of IMF components, proton velocity and density in SW. We have established the relationship of these ionospheric and magnetic disturbances with substorm activity, estimated from $A L$ index. 


\section{DATA}

Possibilities of searching for synchronous ionospheric and geomagnetic disturbances at Kazan station $\left(55.78^{\circ} \mathrm{N}, 49.01^{\circ} \mathrm{E}\right)$ were determined from the presence of ionospheric vertical sounding data with minute resolution for September 1-15, 2014. We carried out the analysis, using data on the F2-layer critical frequency and $H, D, Z$ components.

Within the interval considered, we observed a geomagnetic storm lasting more than three days $\left(D s t_{\min }=-\right.$ $75 \mathrm{nT}$ ). It had a phase of sudden storm commencement (SSC) lasting for $3 \mathrm{hr}$, a main phase lasting for $4 \mathrm{hr}$ (September 12, 20:00 UT - September 13, 00:00 UT), and a recovery phase lasting for more than two days (September 13, 00:00 UT - 15 September, 07:00 UT). The Dst indices for the entire interval are shown in Figure 1 . According to the data, on the remaining days (September 1-11) geomagnetic conditions were quiet.

Note that from September 4 to September 12 experiments were performed on impulse heating of the ionosphere with powerful radio emission at the SURA Ionospheric Heating Facility (Vasilsursk). Hence it was assumed that artificial plasma inhomogeneities may appear in the ionosphere. To exclude such disturbances, for the study we have selected the interval between September 1 and 4, within which the ionospheric heating facility did not work and global geomagnetic conditions remained undisturbed.

Peculiarities of space-time distribution of MS waves have been revealed through the latitude-longitude analysis of variations in geomagnetic field components. For this purpose, we have chosen a number of magnetic stations remote from Kazan station in latitude and longitude. The magnetic stations are listed in Table.

\begin{tabular}{|l|c|c|c|}
\hline Station name & $\begin{array}{c}\text { Geographic } \\
\text { latitude }\end{array}$ & $\begin{array}{c}\text { Geographic } \\
\text { longitude }\end{array}$ & L-shell \\
\hline Sodankylä & $67.37^{\circ} \mathrm{N}$ & $26.63^{\circ} \mathrm{E}$ & 5.3 \\
\hline Port Alfred & $46.43^{\circ} \mathrm{S}$ & $51.87^{\circ} \mathrm{E}$ & 2.8 \\
\hline Kazan & $55.78^{\circ} \mathrm{N}$ & $49.01^{\circ} \mathrm{E}$ & 2.6 \\
\hline Hel & $54.61^{\circ} \mathrm{N}$ & $18.82^{\circ} \mathrm{E}$ & 2.5 \\
\hline San Fernando & $36.67^{\circ} \mathrm{N}$ & $5.50^{\circ} \mathrm{W}$ & 1.3 \\
\hline
\end{tabular}

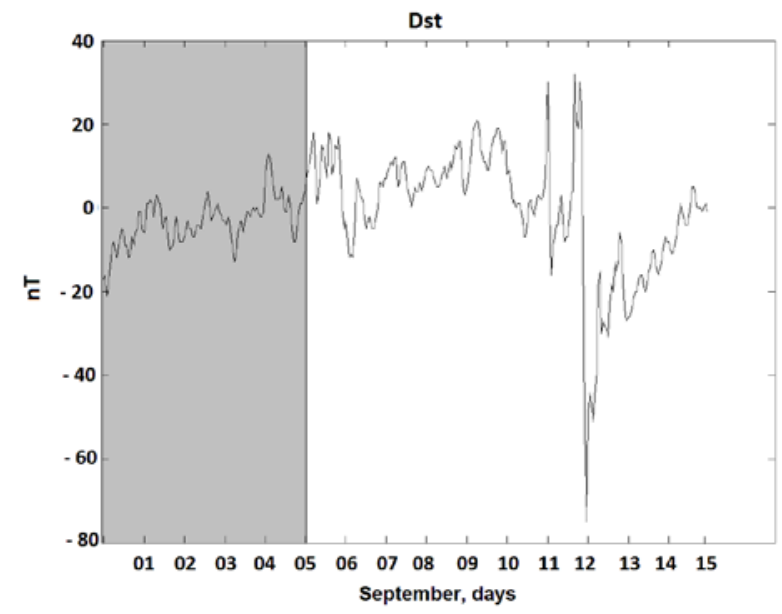

Figure 1. Dst index for September 1-15, 2014. Gray color marks the interval under study

\section{IDENTIFYING MAGNETOSONIC DISTURBANCES IN THE QUIET NIGHT-TIME IONOSPHERE}

The search for simultaneous ionospheric and geomagnetic disturbances in the study of dynamic spectra of the critical frequency and magnetic field components has shown that on September 1, 2, and 4, they had no identical spectral features in the allowed frequency range up to $8 \mathrm{MHz}$. Figure 2 exemplifies dynamic spectra of the critical frequency $f_{0} F 2$ for September 2 and 4 , 2014. According to the given spectra, there are no pronounced ionospheric disturbances at local night-time (+3 GMT).

Moreover, on September 3, 2014, during local nighttime 03:30-05:00 LT (00:30-02:00 UT), there were a series of disturbances with characteristic frequencies in a range from 0.3 to $4 \mathrm{MHz}$ in the dynamic spectrum of the F2-layer critical frequency. An important point is the simultaneous occurrence of a series of such disturbances in the geomagnetic components in the same frequency range. Figure 3 shows dynamic spectra of the F2-layer critical frequency and $H, D, Z$ geomagnetic components for September 3, 2014. Black ovals indicate areas of coincidence of spectral features of the critical frequency and geomagnetic components.

The coincidences of the spectral features demonstrate the synchronous ionospheric and geomagnetic disturbances in the region of the night-time ionosphere. However, dynamic Fourier spectra are not sufficiently informative in determining parameters of a real wave process. In this connection, further investigation into possible synchronization of parameters of these disturbances was carried out by analyzing wavelet spectra. Note that the choice of the basis for the wavelet analysis to be used in the time-frequency expansion affects the final time and frequency resolution of the result. At the same time, the choice of the basic function cannot change the basic characteristic of the wavelet transform (low frequencies have a good frequency resolution and a bad time resolution; high frequencies, vice versa), but we can slightly improve the overall frequency or time resolution. The general principle of forming the basis for the wavelet transform is to use the scale transform and shifts. By changing the scales by wavelets, we can identify the difference between characteristics at different scales and, by shifts, analyze properties of a signal at different points throughout the range studied. In this paper, we apply the basic Daubechies wavelets of the fourth order. Daubechies wavelets are a family of iteratively calculated wavelets. Peculiarities of the calculation of the wavelet spectrum in the form of a system of equations $\varphi(t)$ and $\psi(t)$ allow us to obtain ultimately two vectors, one of which contains a smoothed signal; and the other, a set of local features. This approach simplifies the identification of characteristic properties of the initial data series since it allows us not only to determine the character and dynamic parameters of a signal, but also to precisely localize its features: spikes, sharp level jumps, etc. 
The basic wavelet in use is described by the system of equations

$$
\left\{\begin{array}{l}
\phi(t)=\sqrt{2} \sum_{k} h_{k} \phi(2 t-k) \\
\psi(t)=\sqrt{2} \sum_{k} g_{k} \phi(2 t-k),
\end{array}\right.
$$

where the function $\varphi(t)$ describes the scaling function, and the function $\psi(t)$ characterizes the form of the wave packet. The calculation of the system for each point at $t$ involves computing the trigonometric polynomial coefficients $h_{k}$ and $g_{k}$ with an iterative cascade algorithm. Figure 4 shows the time scanning of the derived forthorder functions.

Figure 5 depicts wavelet spectra of the critical frequency $f_{0} \mathrm{~F} 2$ and $H, D$ geomagnetic components for Kazan station, calculated for September 3, 2014 at night time (from 00:00 to 02:00 UT). Black arrows denote coincidences of maxima of ionospheric and geomagnetic disturbances of the $H$ component from 01:17 to 01:55 UT. The best coincidence of the disturbances under study was noted for periods from 15 to $30 \mathrm{~min}$. Figure 5 does not show the wavelet spectrum for the $Z$ geomagnetic component since its spectral maxima do not coincide with $f_{\mathrm{o}} \mathrm{F} 2$ in the given interval. The spectral maxima of geomagnetic disturbances of the $D$ component in the interval under study are ahead of the maxima noted for the critical frequency and $H$ component. Then, synchronous ionospheric and geomagnetic disturbances were found from $f_{0} \mathrm{~F} 2$ and $H$ data.

As derived from the results, synchronous ionospheric and geomagnetic disturbances are characteristic of the interval considered. The typical periods of the detected MS disturbances belong to the ULF range and are within $35-50 \mathrm{~min}$. The fact that the simultaneous disturbances of $f_{\mathrm{o}} \mathrm{F} 2$ and geomagnetic components have similar features allows us to assume that they have MS nature.

\section{SPATIAL ANALYSIS OF DISTRIBUTION OF MS WAVES CONSIDERED}

It has been noted above that the generation of MS waves in Earth's magnetosphere can be caused by external and internal magnetospheric sources. In any case, the ultralow-frequency wave process of interest involves the entire magnetosphere.

The nearest in longitude to Kazan is Port Alfred Observatory $\left(46.4^{\circ} \mathrm{S}, 51.8^{\circ} \mathrm{E}\right)$, which is located at a magnetoconjugated point. Figure 6 shows spectra of the critical frequency (Kazan) and $H$ component, calculated from per minute data acquired at Port Alfred Observatory on September 3, 2014, from 00:00 to 02:00 UT. Black arrows indicate coincidences of maxima of ionospheric and geomagnetic disturbances of the $H$ component in the interval 15-30 min.

The result of the coincidence of the spectral maxima of the critical frequency at Kazan station and the $H$ component at Kazan station and Port Alfred Observatory, located at magnetoconjugated points, suggests the connection of the wave phenomenon to a corresponding geomagnetic field line.

The problem of whether the waves of interest belong to the SMS class, which are related to the geomagnetic field line, or to the class of isotropic FMS waves can be solved by analyzing wavelet spectra of disturbances recorded at stations whose latitudes are different from the latitude of Kazan.
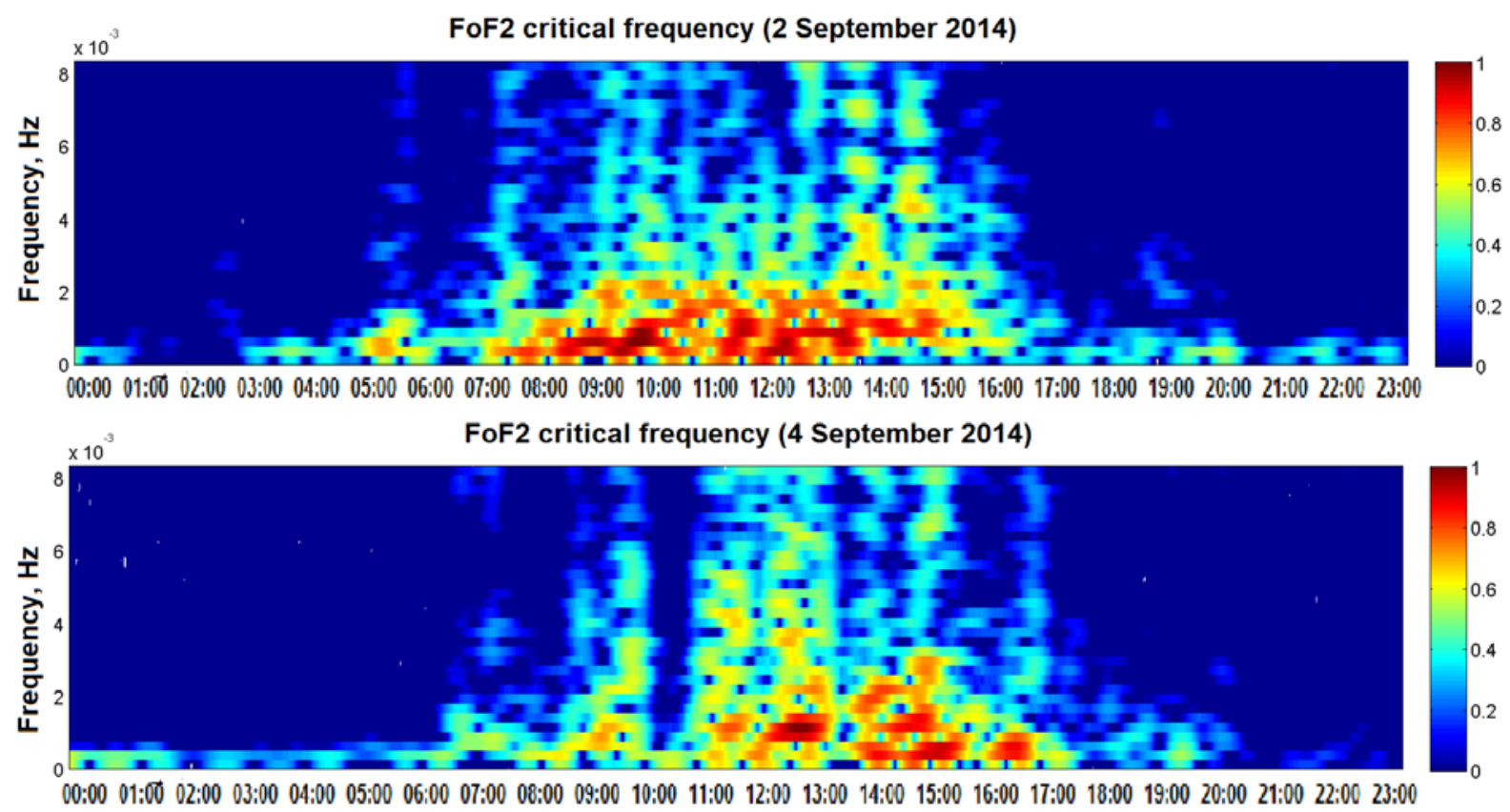

Figure 2. Dynamic spectra of the F2-layer critical frequency for September 2, 2014 (top panel) and September 4, 2014 (bottom panel); time is given in UT 

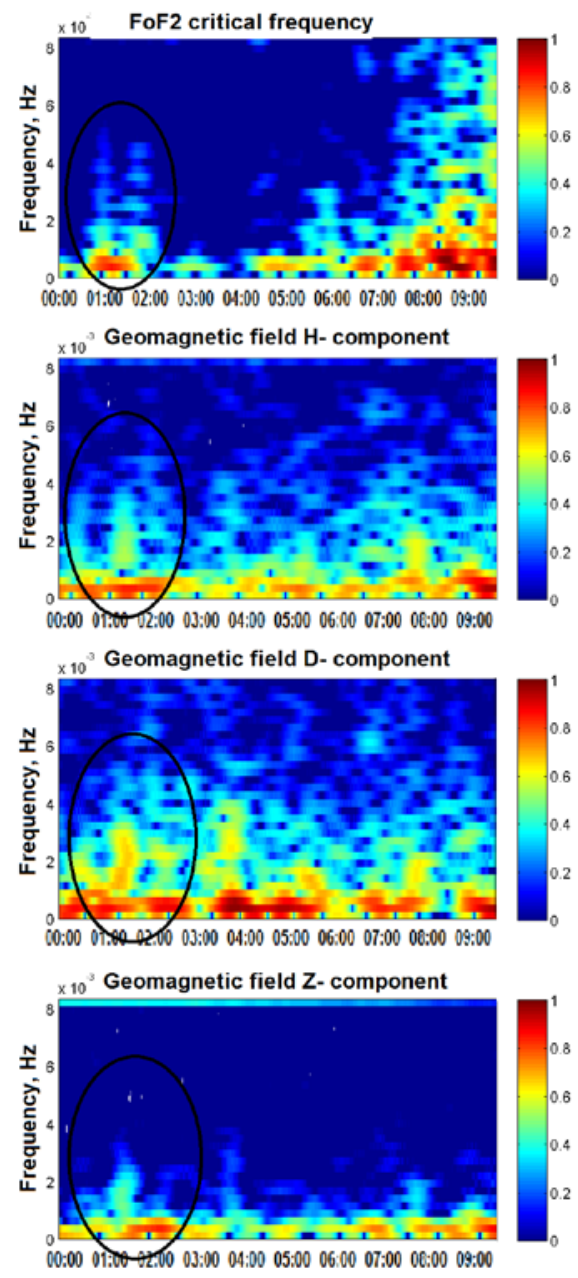

Figure 3. From top to bottom: dynamic spectra of the F2layer critical frequency, $D, H$, and $Z$ components for September 3 , 2014. Black ovals indicate areas of coincidence of spectra features
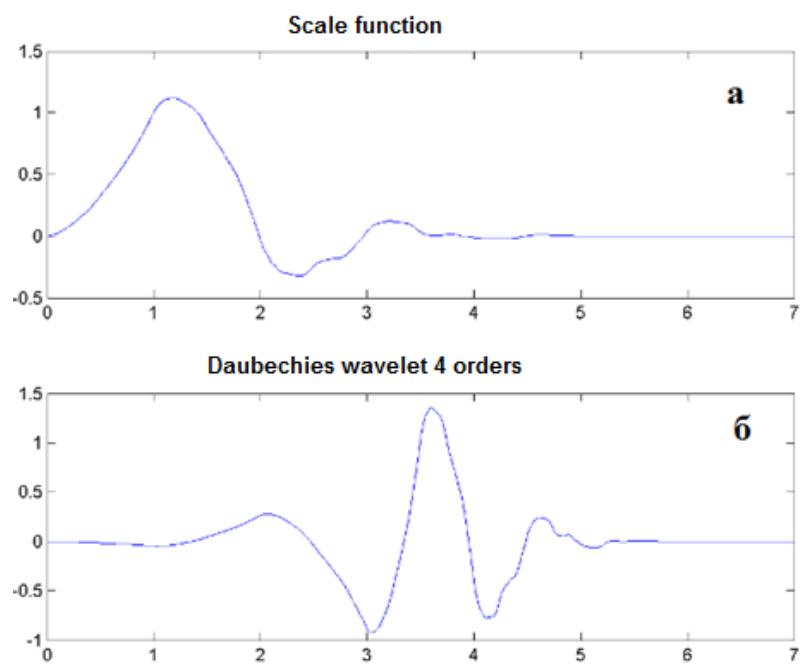

Figure 4. Time scanning of the scaling function (a) and fourth-order Daubechies wavelet $(b)$
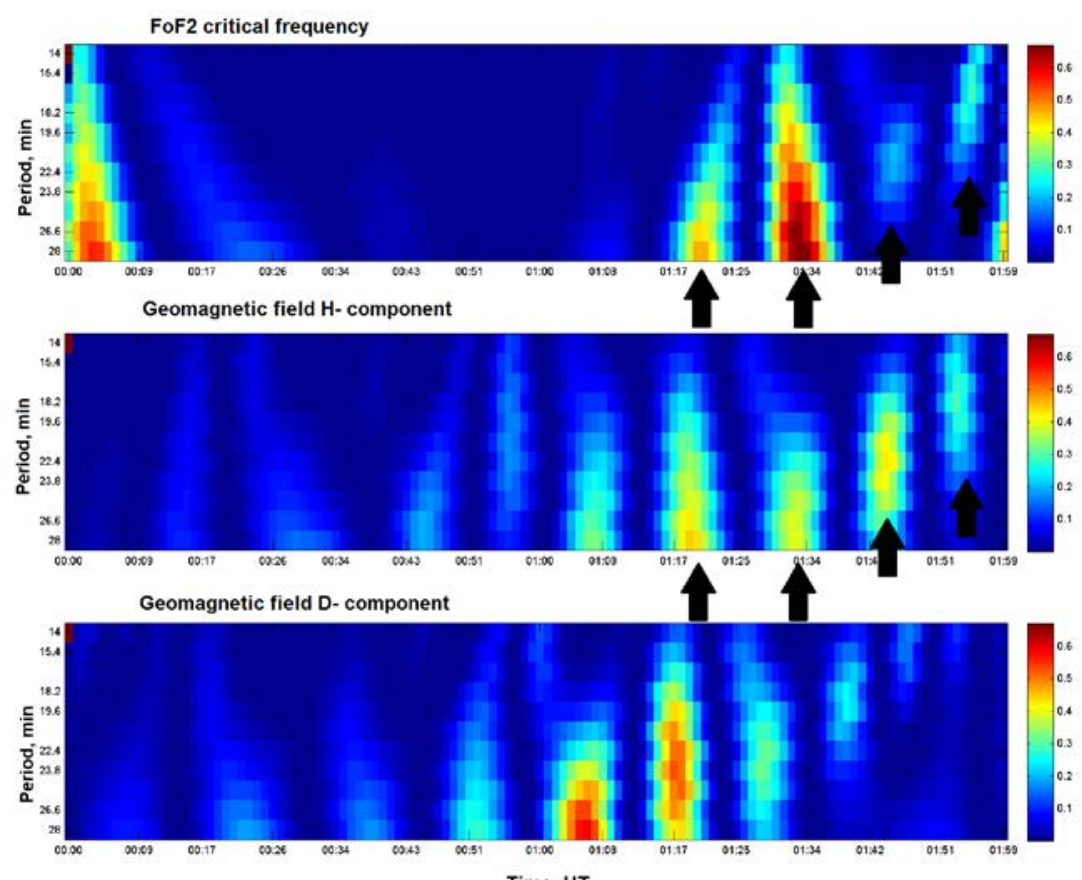

Figure 5. From top to bottom: wavelet spectra of the F2-layer critical frequency, $H$ and $D$ geomagnetic components for September 3, 2014. Black arrows mark a coincidence of spectra maxima in the interval between $f_{\mathrm{o}} \mathrm{F} 2$ and $H$ disturbances 

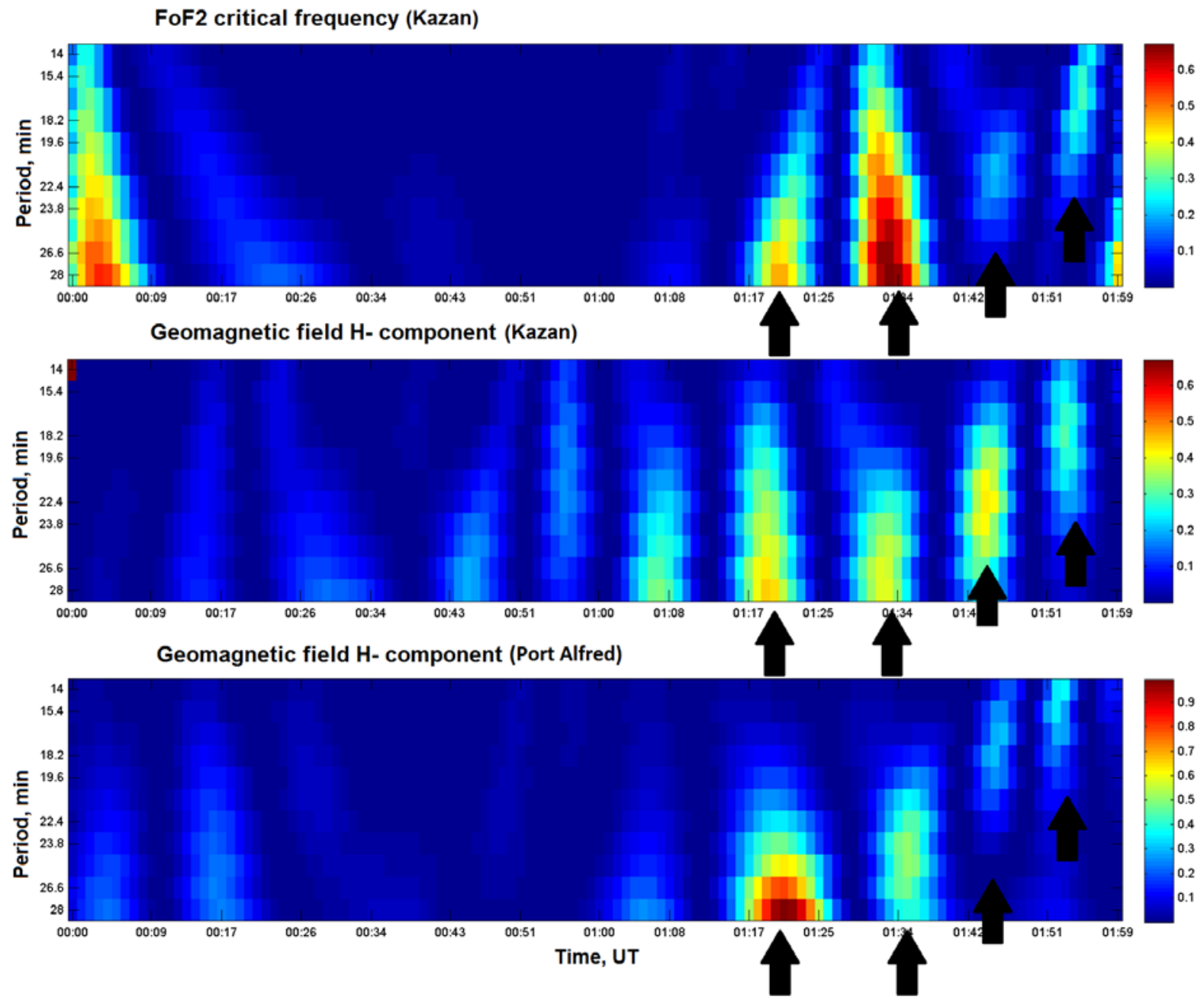

Figure 6. From top to bottom: wavelet spectra of the F2-layer critical frequency registered at Kazan station, $H$ component recorded at Kazan station, and $H$ component recorded at Port Alfred Observatory for September 3, 2014. Black arrows indicate a coincidence of spectral maxima in the interval under study
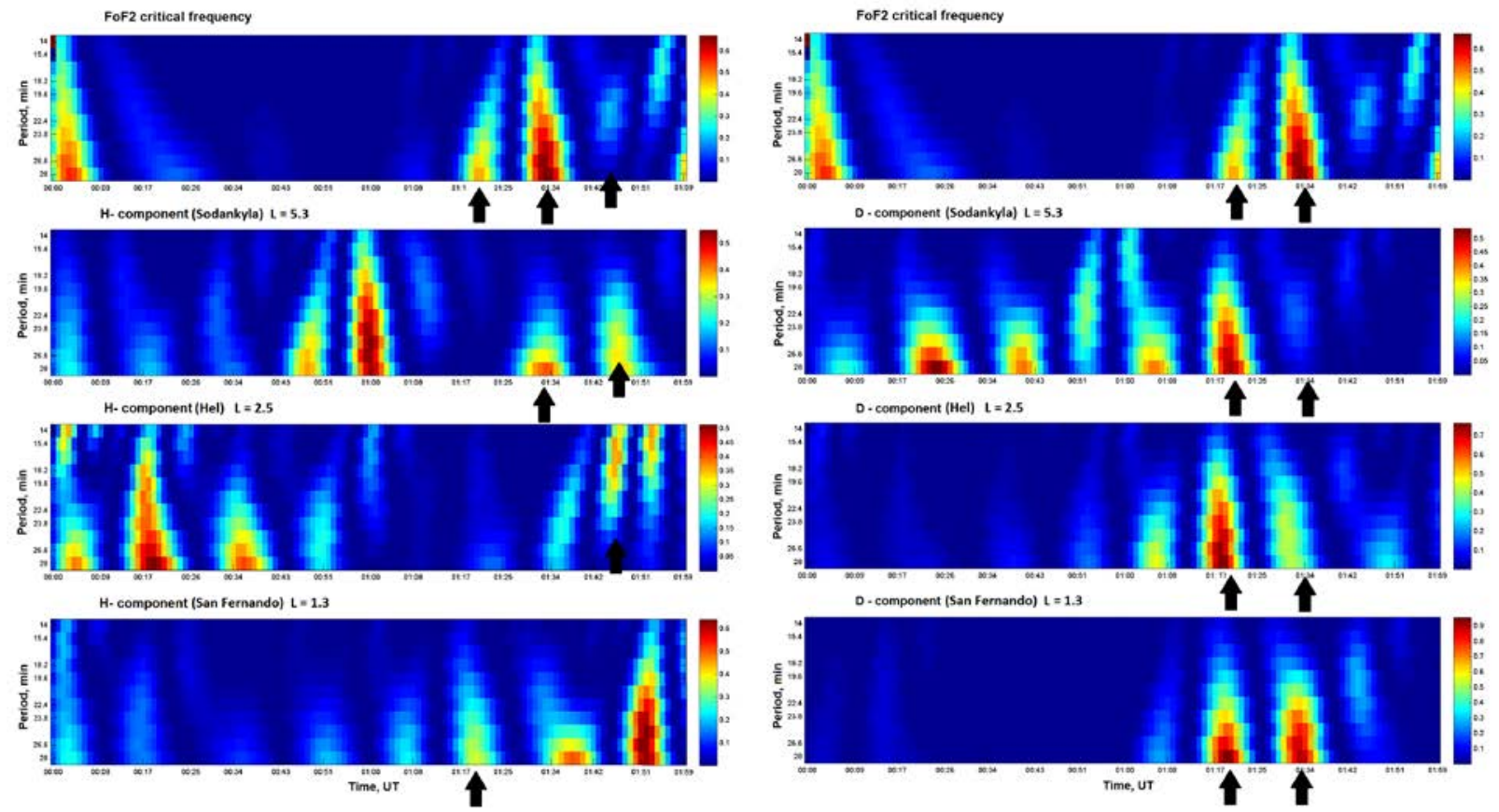

Figure 7. Wavelet spectra of $f_{\mathrm{o}} \mathrm{F} 2$ at Kazan station $(a, e), H$ component $(b-d)$ and $D$ component $(f-g)$ at Sodankyla, Hel, and San Fernando stations. Arrows denote coincidences between the $f_{0} \mathrm{~F} 2$ disturbances in Kazan and magnetic components at the selected stations 

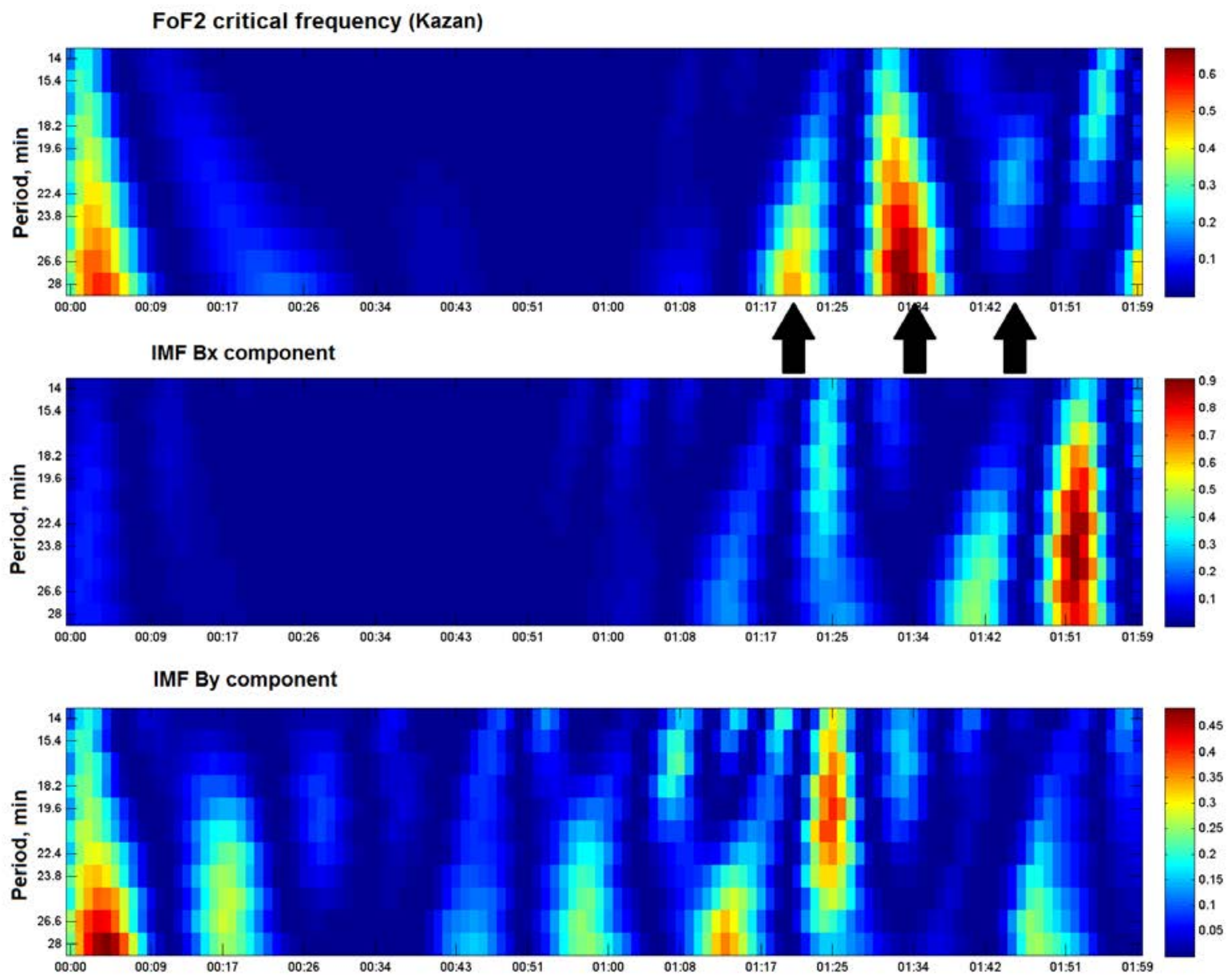

IMF Bz component

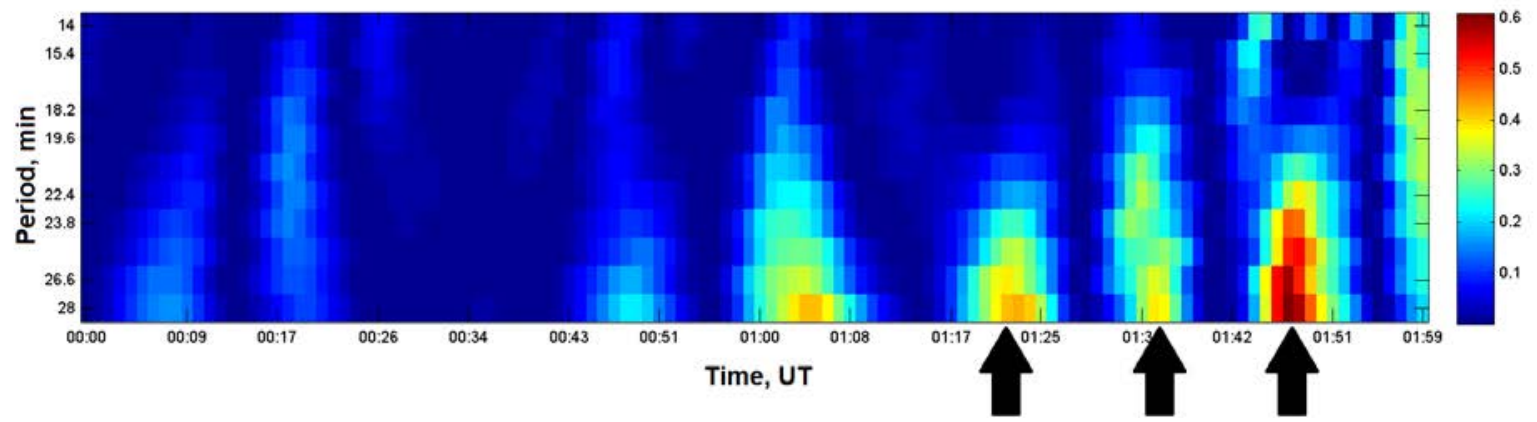

Figure 8. Wavelet spectra of disturbances of the F2-layer critical frequency and $B_{x}, B_{y}, B_{z}$ components for September 3, 2014. Arrows indicate areas of coincidence of spectral features of $f_{0} \mathrm{~F} 2$ and $B_{z}$

Figure 7 shows the wavelet spectra of the critical frequency $f_{0} \mathrm{~F} 2$ over Kazan, as well as horizontal and azimuthal components of the geomagnetic field at stations selected in a latitude range $36-67^{\circ} \mathrm{N}$ (see Table).

According to the data presented in Figure 7 (left panel), the first three of the critical frequency spectral maxima considered (Kazan, $L=2.6$ ) coincide with the $H$ component maxima at magnetic stations in another longitude. The first $f_{\mathrm{o}} \mathrm{F} 2$ maximum at Kazan station ( 01:17 UT) coincides with the maximum of the $H$ component recorded at the low-latitude station San Fernando; the second maximum ( 01: $34 \mathrm{UT})$, with the maximum at the high-latitude station Sodankyla; the third $f_{0}$ F2 maximum ( 01:45 UT), with the $H$ component maximum at the high-latitude and mid-latitude stations
Sodankyla and Hel.

Note that all these $f_{0} \mathrm{~F} 2$ disturbances at the midlatitude station Kazan reflect in the horizontal magnetic component of the stations located at other latitudes and longitudes.

The analysis of disturbances of the azimuthal $D$ component at the stations involved (Figure 7 , right panel) shows that the first two Kazan maxima of $f_{0}$ F2 ( 01:17 UT and 01:34 UT) reflect in $D$ components at all other magnetic stations located almost along one magnetic meridian.

Thus, between $\sim 01: 17$ and 01:45 UT there are disturbances recorded in the horizontal geomagnetic component at stations Kazan, Sodankyla, Hel, and San Fernando, within a large spatial region. This allows us to class them as FMS disturbances. 


\section{POSSIBLE CAUSES OF MS DISTURBANCES IN THE NIGHT-TIME IONOSPHERE}

It has been noted above that the synchronization of ionospheric and geomagnetic disturbances we have identified can be explained by propagation of MS waves through the region under study in the vicinity of Kazan station. Let us find possible causes of the disturbances. An extramagnetospheric cause may be low-frequency oscillations recorded in SW with 15-30 min periods and arising in it due to magnetogravitational disturbances which depend on solar activity. Such oscillations in SW and IMF parameters can be responsible for the occurrence of magnetospheric-ionospheric oscillations manifesting themselves in synchronous disturbances of the F2-layer critical frequency and geomagnetic components. Parameters of disturbances of SW velocity $V$, proton density $P$, and IMF $B_{x}, B_{y}$, and $B_{z}$ components in the frequency range of interest were analyzed within the time interval considered, through spectral wavelet analysis. The wavelet spectra obtained were compared with the previously observed disturbances of the critical frequency and geomagnetic field at Kazan station.

Figure 8 shows wavelet spectra of $f_{0} \mathrm{~F} 2$ at Kazan station (upper panel) and $B_{x}, B_{y}, B_{z}$ for the interval considered. Arrows indicate areas of synchronization of disturbances of these parameters. The results show that there is a coincidence of the spectral features for $f_{0} \mathrm{~F} 2$ and $B_{z}$ in the interval 15-30 min. For $B_{x}$ and $B_{y}$ there are no such coincidences.

This suggests that the onset of these disturbances in the night-time ionosphere can be associated with longperiod oscillations of the IMF vertical component.

It is known that the orientation and modulus of $B_{z}$ component largely determine the global and high-latitude geomagnetic disturbances. The latter fact is examined, for example, in [McPherron et al., 1973]; the authors have noted that the substorm onset phase is closely related to the southward turning of $B_{z}$ component. During this period, energy is accumulated in the magnetotail; then it is dissi-
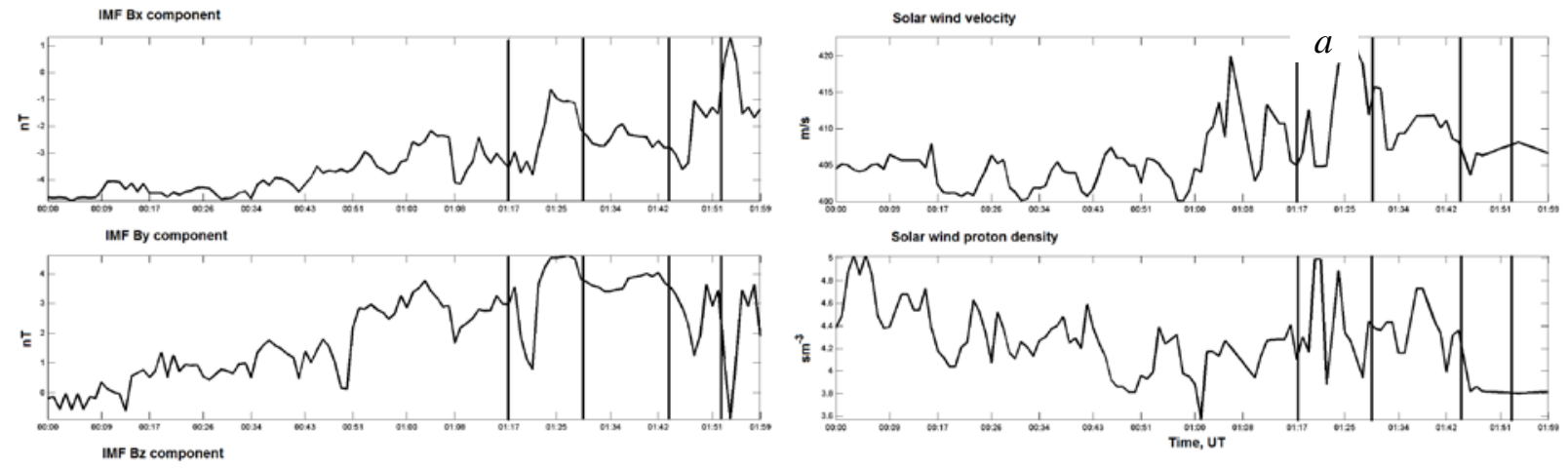

pated during the substorm development phase. Lyons [1996] has suggested that most magnetospheric substorms are triggered by a decrease in the large-scale electric field transferred from SW to the magnetosphere. The main cause of the decrease in the electric field is the northward turning of the IMF vertical component. However, Henderson et al. [1996] has noted that substorms can also occur in the absence of noticeable abrupt changes in the SW and IMF parameters. Thus, the question about the influence of $B_{z}$ direction, its modulus, and duration of retaining certain values on substorm onset processes is still debatable. Peculiarities of the connection of this component with the substorm activity of the magnetosphere have been discussed in many works, for example, [Barkhatov et al., 2017; Vorobyov et al., 2016; Henderson et al., 1996].

Thus, the onset of ionospheric and geomagnetic disturbances in the night-time magnitosphere can be caused by the development of high-latitude substorm processes. In this case, SW and IMF parameters exhibit abnormal behavior, thus allowing us to identify phases of onset, development, and decay of an auroral substorm. In this connection, we have analyzed the dynamics of the $B_{x}, B_{y}$, and $B_{z}$ components (left panel) and SW parameters (proton density and velocity) (right panel) in the interval of interest. In Figure 9, black vertical lines indicate coincidences of spectral features of $f_{0} \mathrm{~F} 2$ and $H$ component at Kazan station.

The study of the dynamics of proton density variations in SW shows that up to 00:45 UT (+3 GMT for Kazan) the proton density was high, then decreased, and reached the minimum value at 01:00 UT. At 01:00-02:00 UT, there was a general increase in SW velocity, which persisted throughout the interval. In addition, at $\sim 01: 00 \mathrm{UT}, B_{z}$ values changed from small negative values to positive ones. This very situation, according to [Barkhatov et al., 2017; Morley, Freeman, 2007], corresponds to the conditions for substorm development.

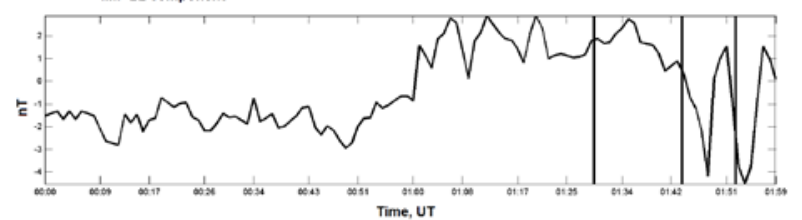

Figure 9. IMF Bx, By, Bz components (a), SW velocity and density (b) at 00:00-02:00 UT for September 3, 2014. Vertical black lines show coincidences of spectral features of $f_{\mathrm{o}} \mathrm{F} 2$ and $H$ component at Kazan station 


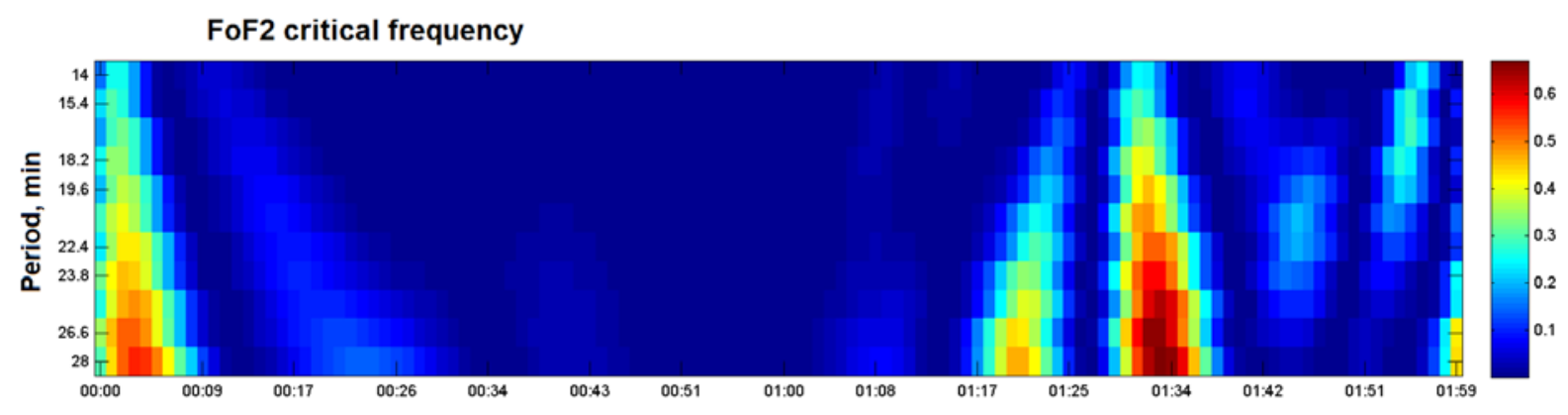

Geomagnetic field H- component

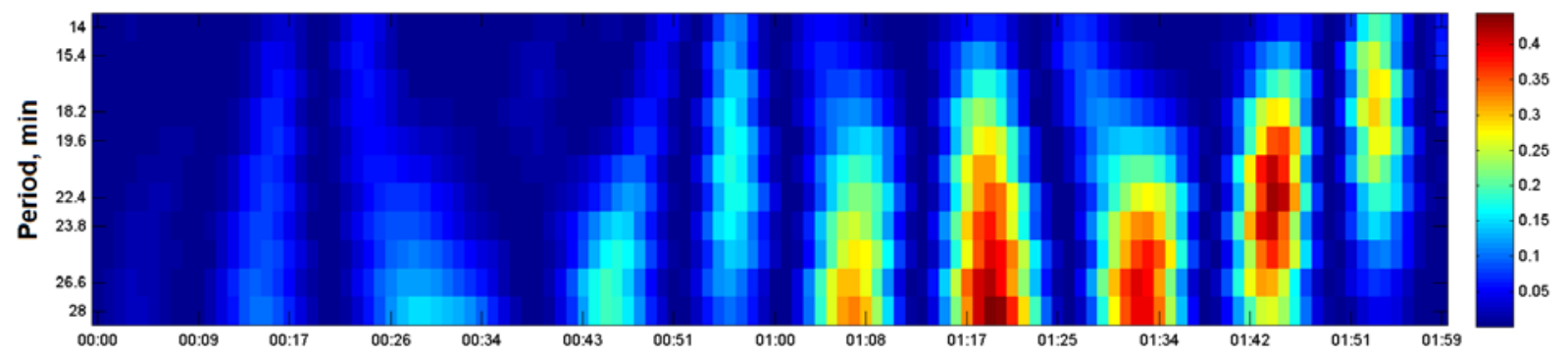

AL

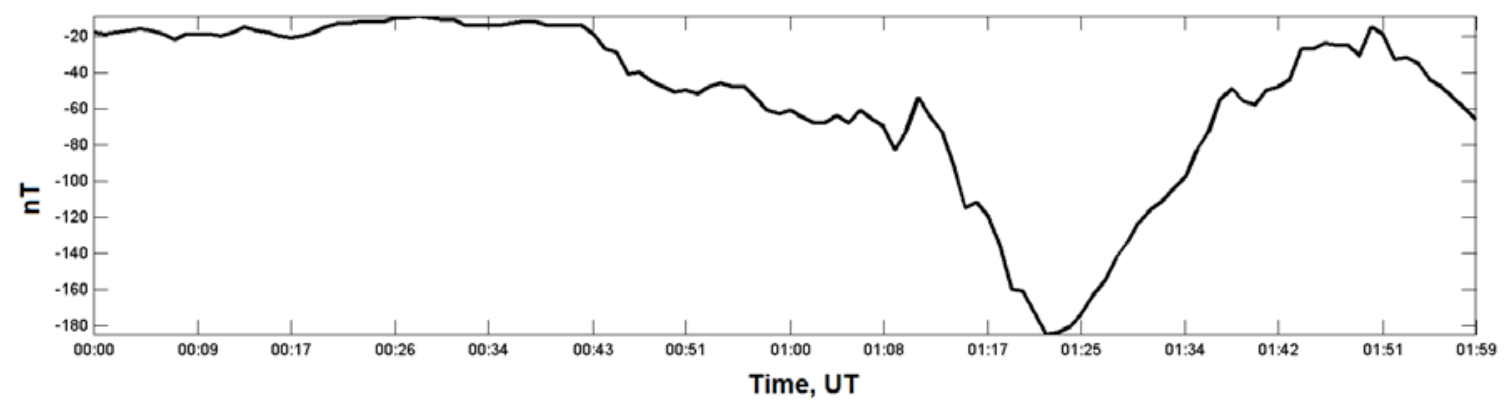

Figure 10. From top to bottom: wavelet spectra of disturbances of $f_{0} \mathrm{~F} 2, H$ component, and $A L$-index variations for September 3, 2014.

Moreover, substorm activity periods can be identified by analyzing the dynamics of auroral activity indices $(A U, A L)$. The interval of interest corresponds to the night-time magnetosphere, in which the western electrojet $(A L)$ is localized. Figure 10 shows wavelet spectra of $f_{\mathrm{o}} \mathrm{F} 2$ and horizontal geomagnetic component at Kazan station versus $A L$ index variations. The ionospheric disturbances under study, which occur with disturbances of geomagnetic components, are within 01:17-01:55 UT.

The dynamics of the $A L$ index suggests that during the period there was a bay-like disturbance preceded by a quiet period ( $A L \sim-20 \mathrm{nT}$ ). From 00:43 to 01:20 UT, the index decreased, reached a minimum of $\sim-180 \mathrm{nT}$, and then gradually increased for half an hour to -20 nT.

Such a dynamics indicates the development of substorm activity in the auroral region of the night-time ionosphere. All the synchronous $f_{\mathrm{o}} \mathrm{F} 2$ and geomagnetic disturbances of interest are within the substorm.

Thus, the spectral analysis of the IMF components and SW parameters has shown that the extramagnetospheric source of the ionospheric and geomagnetic MS disturbances under study can be IMF $B_{z}$ disturbances. This occurs against an increase in SW velocity and an earlier increase in proton density. This very situation in IMF and SW meets the substorm development conditions.
Simultaneously with the substorm, the field lines are stretched into the geomagnetic tail, which undergo the ultralow-frequency vibration produced by the disturbed magnetized SW. Then, one of the sources of MS waves in the frequency range considered may be substorm activity [Belakhovsky et al., 2015] caused by SW disturbances. The MS disturbances recorded over a large spatial region can be generated by instability of the western electrojet involved in the substorm process as an element of a large-scale three-dimensional current system - the Substorm Current Wedge (SCW).

\section{CONCLUSION}

The results of the studies demonstrate that synchronous ionospheric and geomagnetic disturbances in the class of Pi3 pulsations can exist in middle latitudes at local nighttime under global geomagnetically quiet conditions. This has been revealed by comparing spectral patterns of the critical frequency $f_{\mathrm{o}} \mathrm{F} 2$ over Kazan station with geomagnetic components over a large spatial region including high, middle, and low latitudes. We have identified the most probable extramagnetospheric cause of the MS disturbances detected, which manifests itself during a substorm and is related to IMF $B_{z}$ variations. Let us summarize briefly the main results of the work: 
1. We have found coincidences of spectral features of dynamic Fourier spectra of the F2-layer critical frequency and $H, D, Z$ components at Kazan station at local nighttime (00:00-02:00 UT, 03:00-05:00 LT) for September 3, 2014. At the same time, there were no similar disturbances on September 2 and 4 under the same geomagnetic conditions. Thus, we have demonstrated that synchronous ionospheric and geomagnetic disturbances can occur in middle latitudes.

2. We have used the wavelet analysis to determine characteristic periods of these disturbances, which lie in the range of ULF oscillations and vary from 15 to 30 min. In this case, coincidences of spectral features are noted for $f_{\mathrm{o}} \mathrm{F} 2$ and $H$ disturbances at Kazan station, thus allowing us to suggest that they have MS nature.

3. We have classed the disturbances of interest as FMS waves by analyzing coincidences of spectral features of $f_{\mathrm{o}} \mathrm{F} 2$ over Kazan with the disturbances of the $H$ and $D$ components at magnetic stations differing from Kazan in longitude and latitude.

4. We have revealed the synchronization of previously observed ionospheric and geomagnetic disturbances at Kazan station with disturbances of the IMF $B_{z}$ component. We can assume that long-period $B_{z}$ oscillations reflect in the mid-latitude ionosphere and geomagnetic components. We have established that in the event considered this phenomenon emerges during the substorm period.

Thus, the existence of synchronous ionospheric and geomagnetic disturbances in the night-time mid-latitude ionosphere can be caused by an extramagnetospheric source, which in this case may be represented by disturbances of the IMF $B_{z}$ component. The resulting change in the $B_{z}$ orientation, an increase in SW velocity, and an earlier increase in proton density create conditions for substorm development. Simultaneously with the development of substorm activity, field lines stretch into the geomagnetic tail, which are disturbed by ULF oscillations of magnetized SW. The FMS disturbances detected in a large spatial region can be generated by the western electrojet instability associated with substorm development.

We are grateful to Akchurin A.D. and Yusupov K.M. for providing us with ionospheric sounding data from Kazan station.

The work was supported by RFBR grants No. 16-0500608, No. 16-35-00084 and implemented under State Task of the Ministry of Education and Science of the Russian Federation No. 5.5898.2017/8.9.

\section{REFERENCES}

Barkhatov N.A., Vorobyev V.G., Revunov S.E., Yagodkina O.I. Effect of solar wind dynamics on substorm activity formation. Geomagnetizm i aeronomiya [Geomagnetism and aeronomy]. 2017, vol. 57, no. 3, pp. 251-256. (In Russian).

Barkhatova O.M., Barkhatov N.A., Grigoryev G.I. Detection of magneto-gravity waves in the ionosphere from the analysis of maximum observed frequencies at oblique sounding paths. Izvestiya vuzov. Radiofizika [Transactions of Higher School: Radiophysics]. 2009, vol. 52, no. 10, pp. 761-778. (In Russian).

Barkhatova O.M., Barkhatov N.A., Kosolapova N.V. Distribution of magnetogravity waves during strong earthquakes
$(M>6.5)$ preparation periods. Geomagnetism and Aeronomy. 2015, vol. 55, no. 3, pp. 369-377.

Belakhovsky V.B., Pilipenko V.A., Samsobov S.N. Irregular Pi3 pulsations and their correlation with charged particle fluxes in the magnetosphere and ionosphere. Proc. XXXVIII Annual Seminar "Physics of Auroral Phenomena". Apatity. 2015, pp. 71-74. (In Russian).

Guglielmi A.V., Troitskaya V.A. Geomagnetic pulsations and diagnostics of the magnetosphere. Moscow, Nauka Publ., 1973. P. 208. (In Russian).

Henderson M.G., Reeves G.D., Belian R.D., Murphree J.S. Observations of magnetospheric substorms occurring with no apparent solar wind/IMF trigger. J. Geophys. Res. 1996, vol. 101, no. A5, pp. 10773-10792.

Lyons L.R. Substorms: Fundamental observational features, distinction from other disturbances, and external triggering. J. Geophys. Res. 1996, vol. 101, no. A6. DOI: 10.1029/ 95JA01987, pp. 13011-13026.

McPherron, R. L., Russell C. T., Aubry M.P. Satellite studies of magnetospheric substorms on August 15, 1968: 9. Phenomenological model for substorms. J. Geophys. Res. 1973, vol. 78, no. 16, pp. 3131-3149.

Mishin V.V., Tomozov V.M. Manifestations of KelvinHelmholtz instability. Solar-Terrestrial Physics. 2014, iss. 25, pp. 10-20.

Morley S.K., Freeman M.P. On the association between northward turnings of the interplanetary magnetic field and substorm onsets. Geophys. Res. Lett. 2007, vol. 34, L08104. DOI: 10.1029/2006GL028891.

Skeel R.D., Berzins M. A method for the spatial discretization of parabolic equations in one space variable. SIAM $J$. Scientific \& Statistical Computing. 1990, vol. 11, pp. 1-32.

Vorobyev V.G., Yagodkina O.I., Zverev V.L. Research into isolated substorms: generation conditions and and characteristics of different phases Geomagnetizm i aeronomiya [Geomagnetism and aeronomy]. 2016, vol. 56, no. 6, pp. 721-732. DOI: 10.7868/S001679401606016X. (In Russian).

Vorontsova E., Pilipenko V., Fedorov E., et al. Modulation of total electron content by global Pc5 waves at low latitudes. Adv. Space Res. 2016, no. 57, pp. 309-319.

\section{How to cite this article}

Barkhatova O.M., Kosolapova N.V., Barkhatov N.A., Revunov S.E. Synchronization of geomagnetic and ionospheric disturbances over Kazan station. Solar-Terrestrial Physics. 2017. Vol. 3. No. 4. P. 58-66. DOI: $10.12737 /$ stp-34201706 